\title{
Monitoring the Laser Ablation Process of Paint Layers by PILA Technique
}

\section{Angel Eduardo Villarreal-Villela, L. Ponce Cabrera}

Instituto Politécnico Nacional, Centro de Investigación en Ciencia Aplicada y Tecnología Avanzada Unidad Altamira, Altamira, México Email: avillarrealv1400@alumno.ipn.mx

How to cite this paper: Villarreal-Villela, A.E. and Cabrera, L.P. (2016) Monitoring the Laser Ablation Process of Paint Layers by PILA Technique. Open Journal of Applied Sciences, 6, 626-635.

http://dx.doi.org/10.4236/ojapps.2016.69060

Received: August 24, 2016

Accepted: September 20, 2016

Published: September 23, 2016

Copyright $\odot 2016$ by authors and Scientific Research Publishing Inc. This work is licensed under the Creative Commons Attribution International License (CC BY 4.0).

http://creativecommons.org/licenses/by/4.0/

\begin{abstract}
The spectrum analysis obtained by Fast Fourier Transform of the Photoacoustic Induced by Laser Ablation (PILA) during laser assisted paints removal process is described, in order to identify the presence of paint components on a metallic surface, optimize the ablation rate and propose the method as a cleaning process monitoring. The process was carried out using a low-cost experimental setup which includes a burst-mode Nd:YAG laser, an electret microphone, an audio amplifier device and an oscilloscope, to record the acoustic pulse and analyze it. The samples surface morphology was characterized by Optical Microscopy and Optical Coherence Tomography (OCT) before and after irradiation to visualize the formation of craters. As additional monitoring technique, the Laser Induced Breakdown Spectroscopy (LIBS) was used. The potential of the analysis for qualitative monitoring of coating removal was demonstrated due to the coincidence of the information provided by LIBS and PILA techniques.
\end{abstract}

\section{Keywords}

Laser Induced Breakdown Spectroscopy, Pulsed Laser, Nd:YAG, Acousto-Optical Signal Processing

\section{Introduction}

In 1986, John Asmus [1] discovered how to remove black inlays in white marble using a ruby laser that took advantage of to the absorption and reflection properties of the materials in question. This discovery paved the way for laser cleaning technology in conservation, which offered a significant improvement over conventional technologies due to the absence of direct contact, and also due to the fact that this technology does not require the use of abrasives or chemicals, as well as due to the ability to preserve the 
texture of objects, among others [2]-[4].

In addition to applications in the conservation field, laser cleaning has expanded to other industrial sectors, as a result of the disadvantages of other cleaning technologies, such as ultrasound and power washing. An example of this technology was developed in the semiconductor industry, since the conventional procedures did not provide the results hoped for with micrometrical particles and damaged some of the fragile substrates [5].

The PILA study (photoacoustics induced by laser ablation) performed to analyze the ablation produced by pulsed lasers is not much more than three decades old [6]. In the initial studies, complex transducers were used, as their strengths primarily rested on the detection of ultrasonic waves. Nevertheless, the previous works of Y. F. Lu and collaborative researchers [7] demonstrated the presence of mechanical vibrations in the audible range; hence, they proposed to use less specialized transducers, which translated to a much cheaper device, and just as in the first study, they posited the possibility of detecting the ablation threshold using the PILA technique by correlating the peak-topeak voltage of the first acoustic pulse oscillation with the flow of the laser pulse as well as with its behavior by modifying the number of pulses.

In recent research [8] [9], we can observe how the data captured by the PILA technique is utilized as a monitoring method in selective ablation applications.

Even though they demonstrated the possibility of a direct correlation between the electric signal magnitude and laser fluency, M. Fiedler and P. Hess suggested performing an acoustic pulse analysis by changing the time domain to the frequency domain by applying Fast Fourier Transform (FFT) [10]. In their research, they detected frequency bands that provided quantitative information about the chemical reactions of the gases they were studying in their research.

T. Flores and collaborative researchers [11] detected selective ablation in cactus fruit prickles by monitoring the process using LIBS in order to automate the application developed by M. Arronte and collaborative researchers [12] which uses free-generated laser pulses to de-thorn the opuntia cactus. To this end, they studied the PILA signal generated by FFT analysis with the purpose of identifying when the prickles were completely gone, certain characteristic bands of both materials.

On the other hand, in the work of L. Moreira and collaborative researchers [13], it was demonstrated an innovative approach of LIBS technique, developing a low-cost and portable system for determining the composition of historical constructions. The system includes a multi-pulse emission laser, which underscores the feasibility of using this technology in-situ by using this laser emission mode. The compactness and low prices of this device are the main reasons why we use this configuration for monitoring the paints ablation made in our work.

In resume, in this work the proposal is to qualitatively monitor the ablation of layers deposited onto a metallic surface, utilizing the Fast Fourier Transform (FFT) or the intensity of the sampled photoacoustic signal induced by laser ablation, specifically for the case of multi-pulsed laser emission. For the confirmation of the behavior of PILA 
analysis in these two variants, a low cost LIBS device with multi-pulse emission was used.

\section{Experimental Development.}

The study sample was prepared using an Al paint finish deposited onto a thin sheet of $\mathrm{Cu}$. For the research develop, the set up illustrated in the block diagram of Figure 1 was used. A multi-pulse Nd:YAG laser with a passive Cr:YAG Q:Switch was used as excitation source. This laser emits radiation in $1064 \mathrm{~nm}$ wavelength. Each laser shot is characterized by a pulse train [13], concentrated along the surface of the sample using a $5-\mathrm{cm}$ lens at focal distance. The number of pulses per train varies between 6 and 8 , while the inter-pulse separation is in range $10-20 \mu \mathrm{s}$. The plasma generated is collected by the fiber optic Ocean Optics P600-1-SR and directed onto the USB 4000 Ocean Optics spectrometer (Spectral range: 200 - $900 \mathrm{~nm}$, with resolution of $0.35 \mathrm{~nm}$ ), which begins to capture using an electric signal supplied by the photodetector Thorlabs PDA 10 $A$, and by the use of a delay device this signal can be deferred from the time $t=0$ to intervals from 2 to $50 \mu$ s, for the purpose of evaluating the plasma's progression over time as well as to avoid electronic background. The captured data is then sent to the computer for post-analysis. An electret microphone converts the acoustic pulse into an electrical signal was used in the PILA study. The electret microphone is amplified with an audio amplifier and then sampled with a Tektronix model TDS $1001 \mathrm{~b}$ oscilloscope. The data is then sent to the computer for analysis.

20 laser shots were fired at energy of $60 \mathrm{~mJ}$ per pulse train at a single point. Using LIBS, the emission was detected and identified as characteristic lines in the plasma generated by each train, while during the PILA study, the acoustic pulse was detected for each event, the latter of which was characterized by its most significant oscillation in the time domain. Additionally, for each sample data, the Fast Fourier Transform magnitude was calculated. Information as to the surface morphology of the sample was

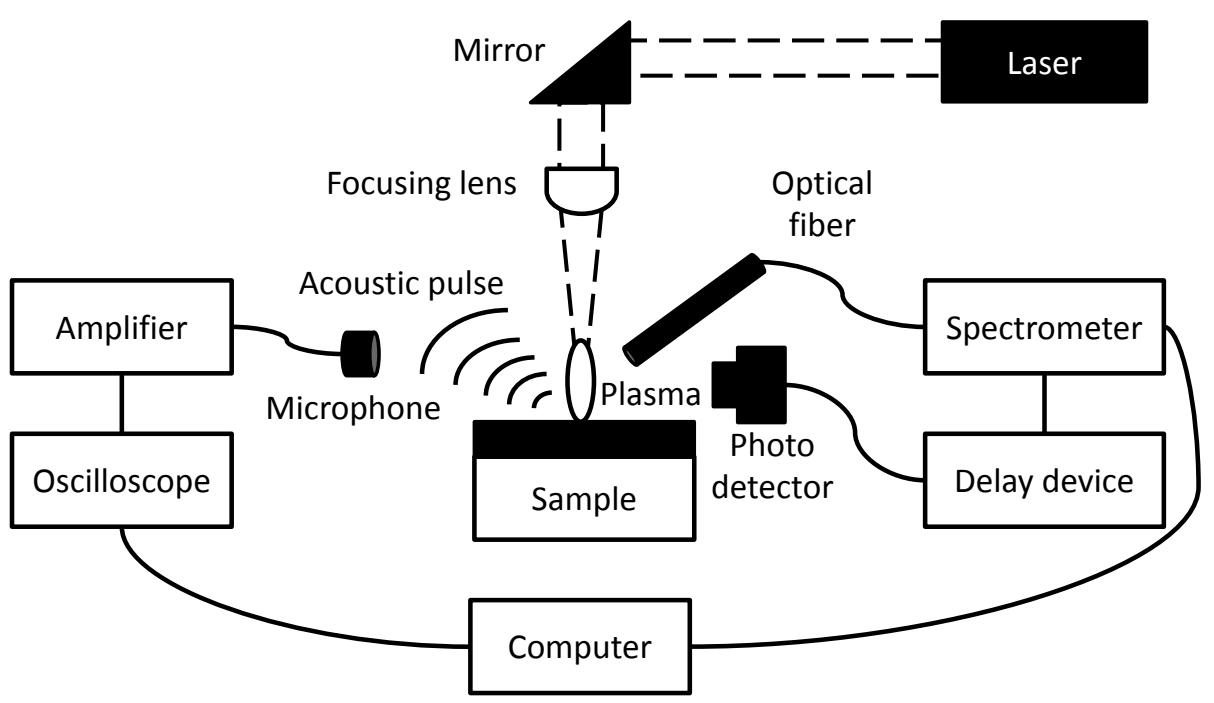

Figure 1. Set up used for the experiment. 
captured before and after the treatment. This was done by magnifying the images using a 100x optical microscope and, additionally, reconstructing the surface of the object using a CALLISTO optical coherence topography device (OCT), provided by Thorlabs.

\section{Results and Discussion}

\subsection{Ablation Experiments}

As mentioned in the experimental development section, a succession of 20 laser shots was fired, each pulse consisting of a train of $6-8$ pulses. The energy of each pulse train was set at $60 \mathrm{~mJ}$, firing the pulses over the same area. The purpose of this procedure was to gradually ablate material until reaching the substrate or even to penetrate to the interior of same, in order to see the transition between the materials. The data obtained is analyzed by each one of the monitoring techniques used: the emission of plasma in LIBS and the acoustic pulse in the PILA analysis.

The plasma emission spectrum was obtained for each laser shot. Figure 2(a) shows a typical spectrum captured on the aluminum paint layer, and in Figure 2(b), a typical spectrum captured on the copper tube. In both cases, various characteristic lines have been identified using for reference the NIST database [14]. Two of these lines, one for each material, were selected for following the depth analysis, these being the Al I 396.15 $\mathrm{nm}$ line for the paint and the $\mathrm{Cu}$ I 521.82 line for the substrate.

Thus, it was possible to construct a profile of intensity depth, using the selected pikes intensity versus number of shots, which is shown in Figure 3. As seen in Figure 3, for the first two shots the presence of $\mathrm{Al}$ emission is more intense than $\mathrm{Cu}$ emission, which demonstrate that the ablation take places on the paint layer. After the second shot, one can begin to see a predominant emission of $\mathrm{Cu}$, the intensity of which gradually increases until it reaches a saturation level at 6 shots. After this point, the $\mathrm{Al}$ intensity begins to gradually decrease, with slight increases and decreases along the way, but

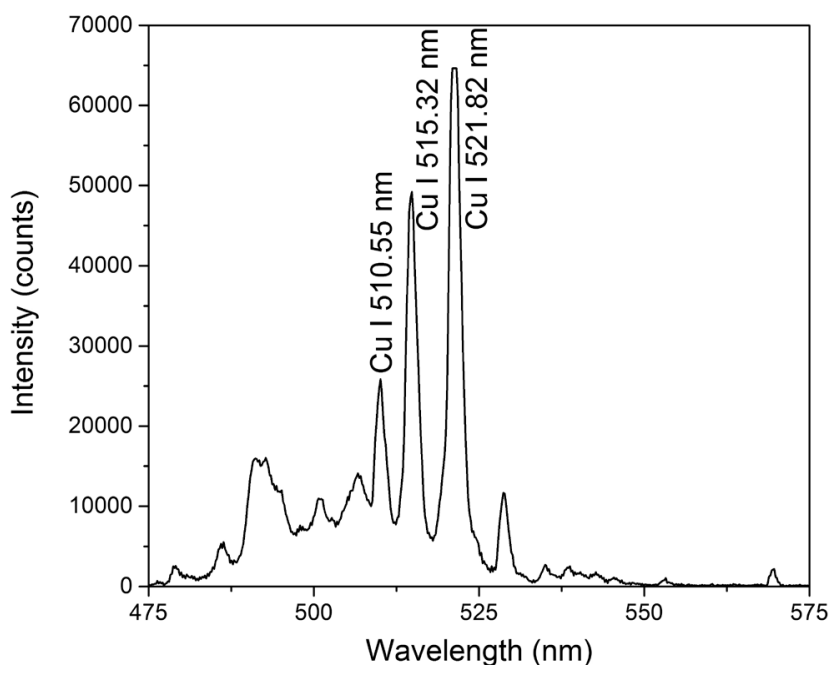

(a)

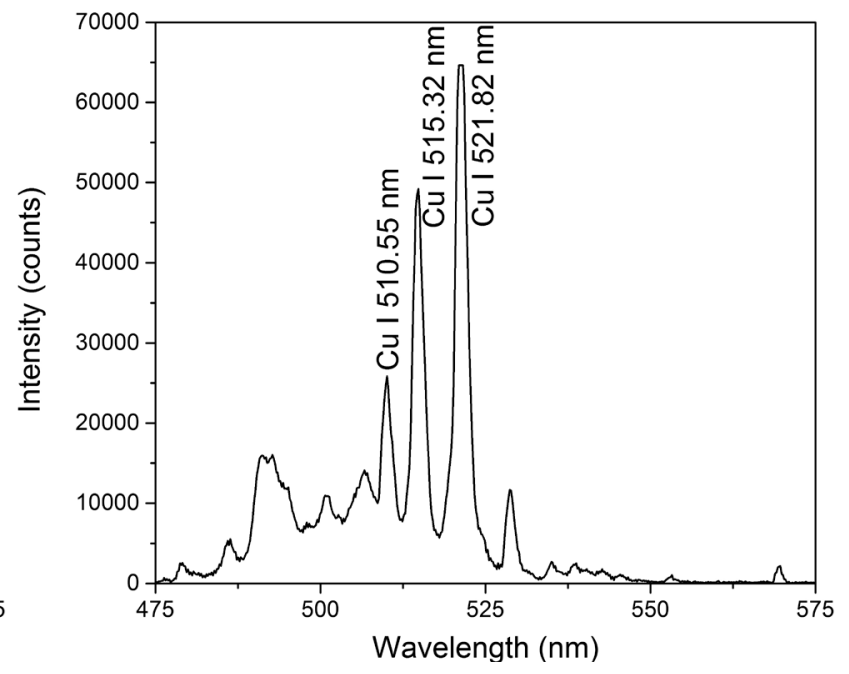

(b)

Figure 2. LIBS spectra: (a) of the paint layer, (b) of the copper tube. 
the $\mathrm{Al}$ intensity does not disappear completely. Ii is clear that after the second pulse, the ablation takes place on the $\mathrm{Cu}$ substrate.

From here on out, the difference in intensity between the copper line and the aluminum line becomes greater, i.e., the intensity of lines diverge. While the aluminum line does not exhibit a uniform behavior, it does show lower intensity. This can be due to the fact that the aluminum is re-solidifying on the surface after having been ejected, and also due to a certain amount of $\mathrm{Al}$ ablation progressing from the boundaries of craters formed during the process, whose diameter would tend to increase as the depth of the successive pulses increase and this can contribute to eventual changes in $\mathrm{Al}$ line intensity.

Twenty acoustic pulses associated with the case at hand in the LIBS section were captured at a sample interval of $4 \mu$ s. Figure 4 shows oscillograms of the first five shots

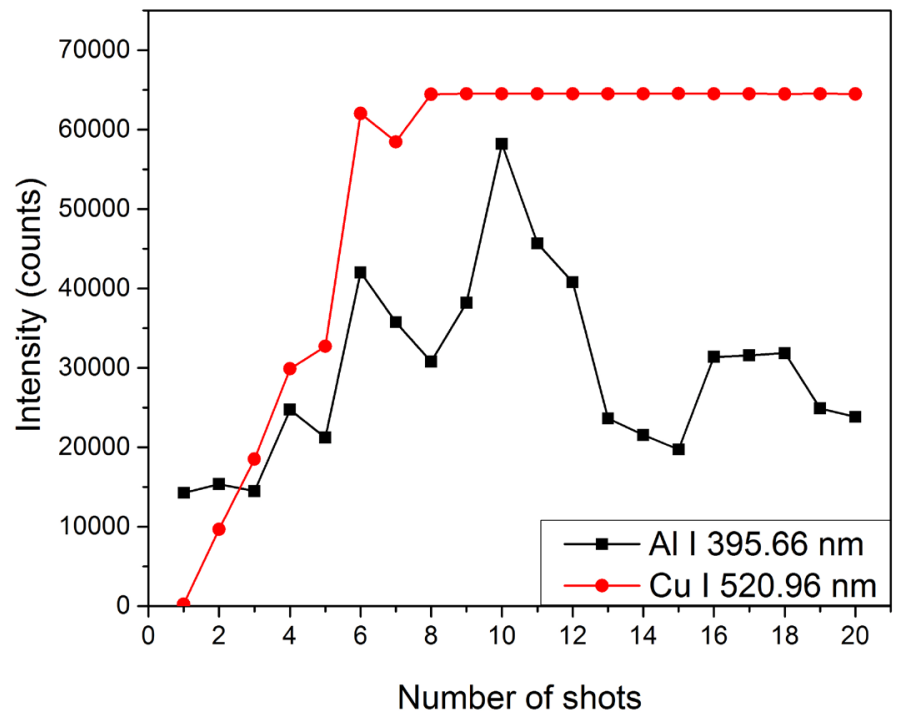

Figure 3. Intensity of two characteristic lines (Cuand $\mathrm{Al}$ ) versus number of laser shots.

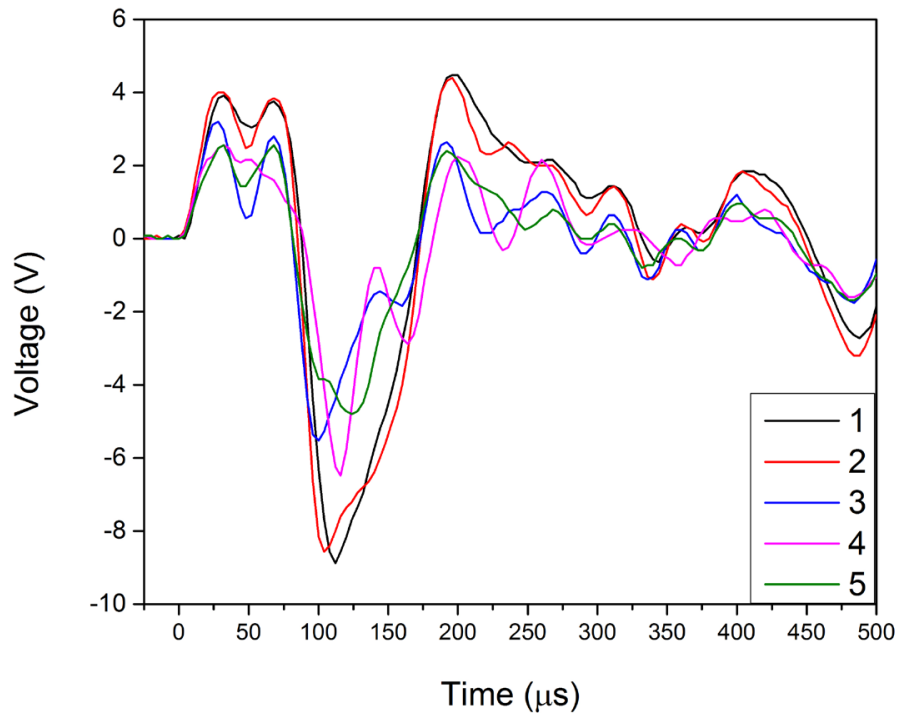

Figure 4. Oscillograms of the first five shots in the sample. 
in order to illustrate the electret microphone response. A small oscillation can be distinguished in the first $50 \mu \mathrm{s}$, after which a major magnitude change occurs. Considering that this is the most significant magnitude for the entire life of the acoustic pulse, we can describe this as the peak-to-peak voltage of the most significant oscillation. This was graphed versus the number of shots and illustrated in Figure 5. The tendency observed here is that for the first two shots, there is maximum amplitude, which diminishes without returning to its original maximum value.

By matching with the observations in the LIBS analysis, there is coincidence between the decrease in amplitude in relation to the investment of the intensity of the selected lines, that suggests the majority ablation of the paint layer.

Another method of visualizing possible changes in the acoustic pulse is to study the frequencies contained in the measured interval by applying the Faster Fourier Transform (FFT) to the sample. In order to obtain the clearest result, the magnitude of the complex numbers corresponding to the frequencies is to be determined. The result of this procedure can be seen in Figure 6, where the results of the first five shots are superimposed on one another. At first glance, additional frequency bands between shots cannot be distinguished, but after the second shot, an overall decrease is observed.

Considering the band of $5000 \mathrm{~Hz}$ the most representative, Figure 7 shows the progression of its relative intensity for the fired shots. A notable difference can be seen in the intensity between the first two shots and the rest, whose value diminishes drastically after the third pulse and maintains essentially stable until the process is completed. This behavior is also, similar to what is observed in the intensity progression of the characteristic line in the LIBS case.

This similar behavior makes the study of PILA suitable for use as an alternative qualitative monitoring method, enabling the distinction between where the ablation ends for one layer and where it begins for the next layer.

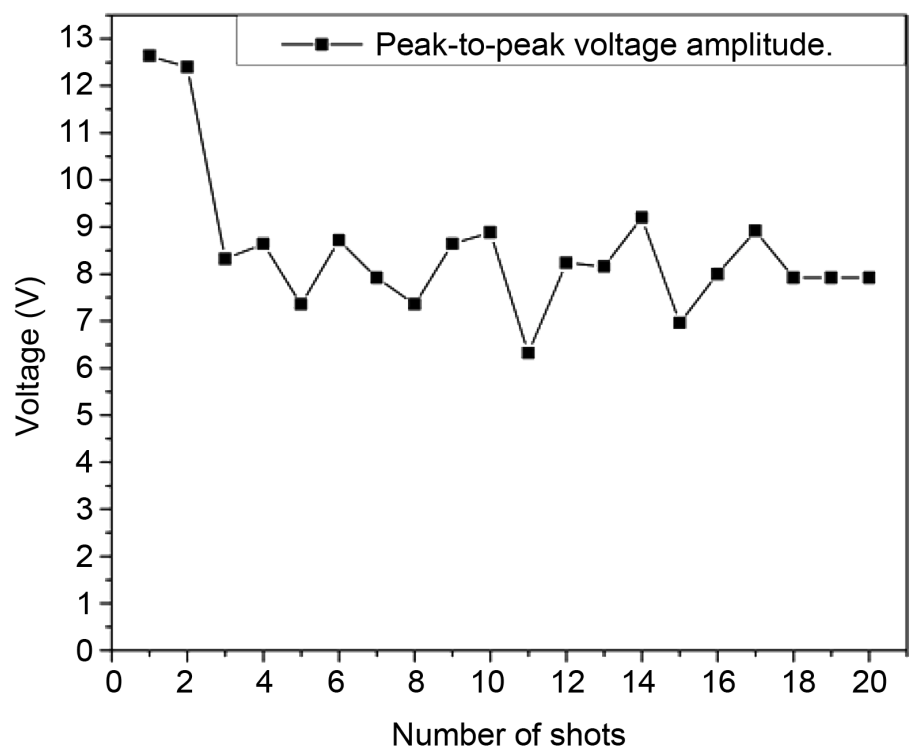

Figure 5. Peak-to-peak voltage tendency of the most significant oscillation. 


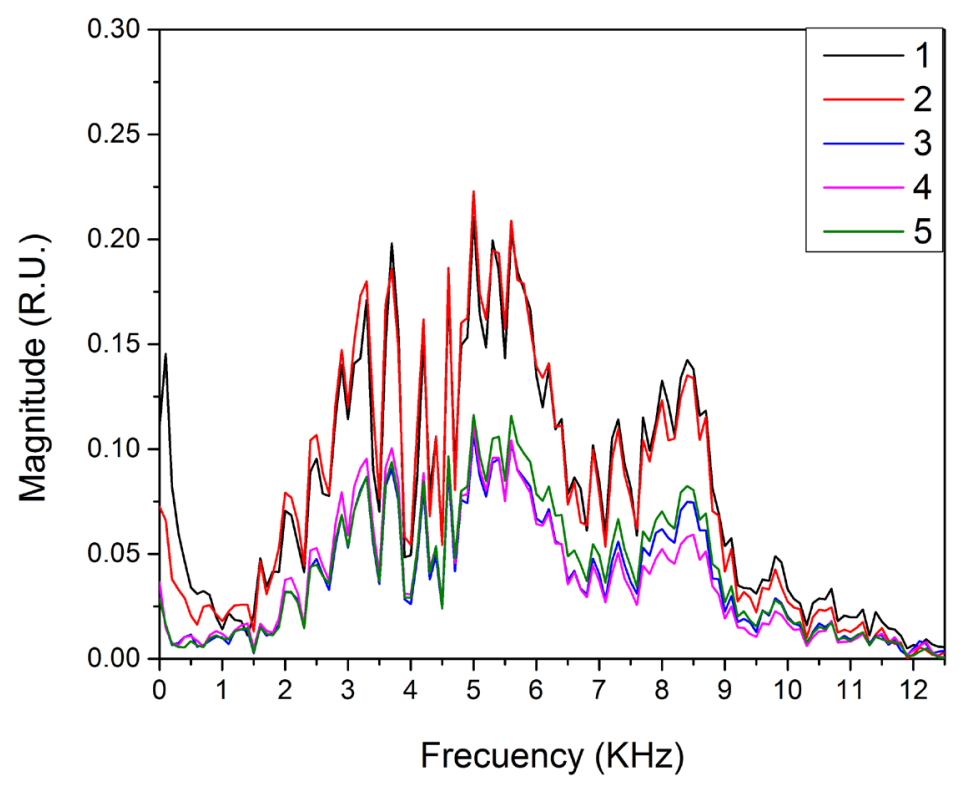

Figure 6. FFT magnitude of the first five shots in the sample.

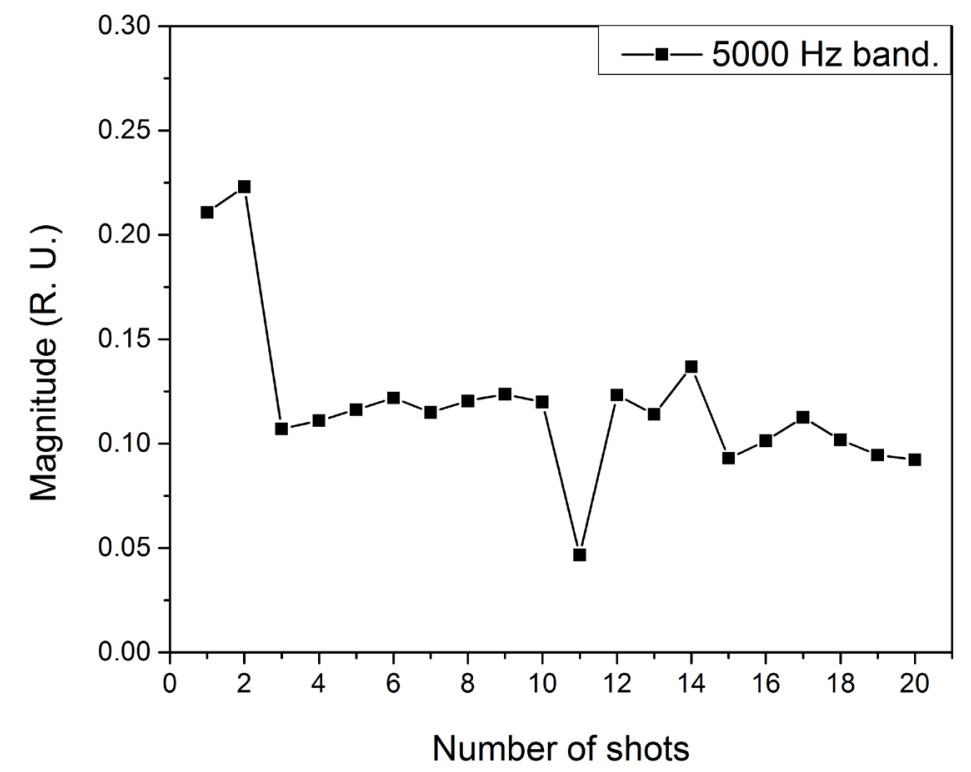

Figure 7. Magnitude tendency of the $5000 \mathrm{~Hz}$ band.

\subsection{Analysis of Surface Morphology}

Figure 8(a) shows an image of the surface of the study samples before the treatment magnified 100x, where one can see that the surface is uniform along the entire surface, this does not have imperfections such as craters or visible layers. Figure 8(b) illustrates a reconstruction of the same surface, generated by the OCT device, which was imaged in an area of $3 \times 3 \mathrm{~cm}$. Therefore, it corroborates the uniformity of the surface shown in Figure 8(a).

Figure 9 shows images after the treatment obtained by magnification at $100 \times$ of the surface by optical microscopy (top pictures), and OCT reconstructions where laser 


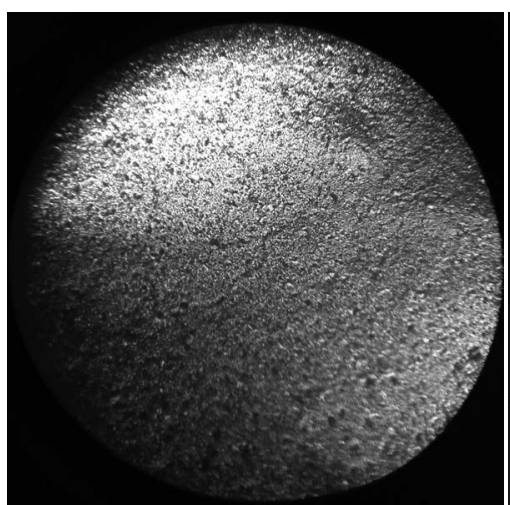

(a)

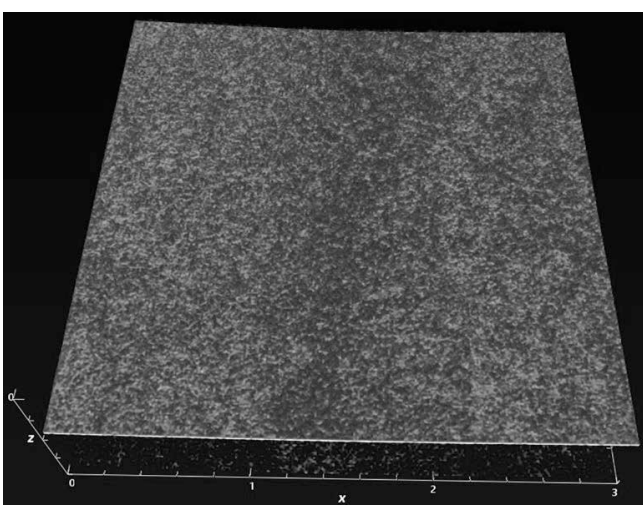

(b)

Figure 8. Images of the surface: (a) magnified by optical microscope at $100 \times$, (b) and OCT tomography.

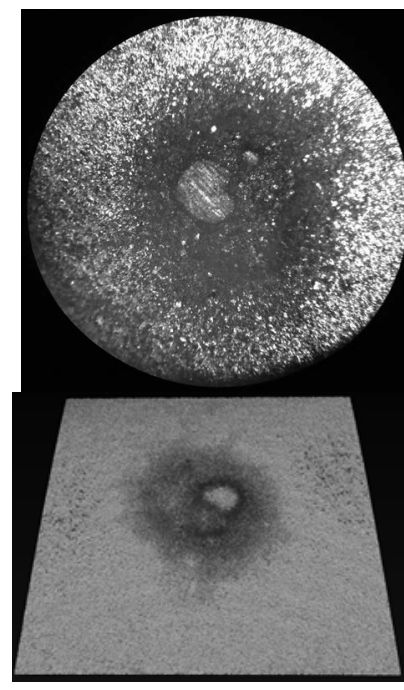

(a)

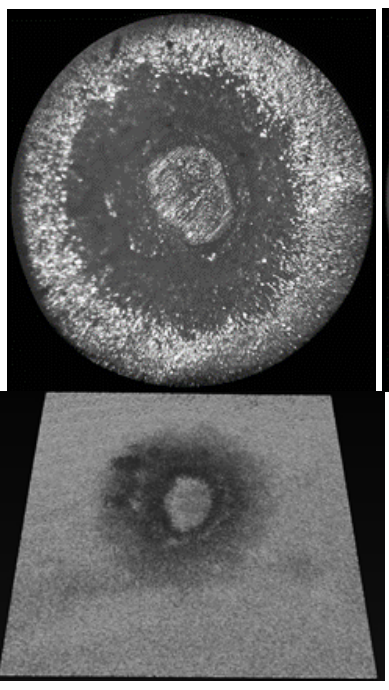

(b)

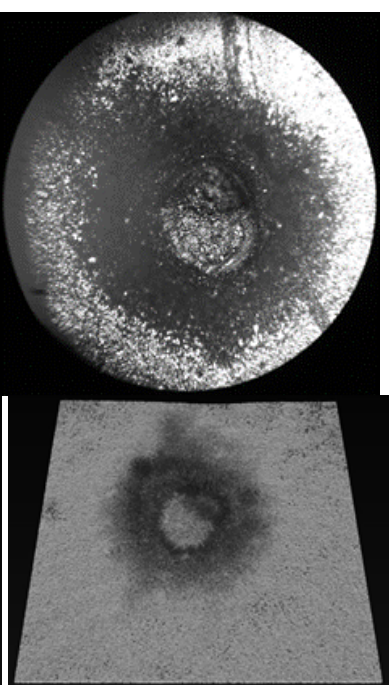

(c)

Figure 9. Images of the surface after: (a) one shot, (b) two shots, (c) three shots.

shots occurred (bottom pictures). As we can see that in Figure 9(a) the crater begins to form, in Figure 9 (b) the paint has been completely removed in the incidence zone of the laser, and in Figure 9(c), the laser finally begins to interact with the substrate. This visual observation are in agreement with the results obtained in both the LIBS and the PILA monitoring techniques, i.e. the optical microscope and the OCT imaging indicate that ablation of the material from the substrate begins with the third shot.

\subsection{Discussion of the Results}

Monitoring the depth of the elemental composition by LIBS has been reported previously for LIBS systems with monopulse excitation [15]. The experiments conducted in this study confirm that in the case of multipulse excitation, LIBS monitoring is still possible, despite the greater structural complexity of the laser pulse and consequently, and despite the greater complexity of the ablation process and acoustic wave formation. 
On the other hand, the use of PILA demonstrates a potential ad depth-profiling low cost and simple method. The information obtained in this PILA study herein was divided into two parts: the amplitude study of the first oscillation of the pulse and the magnitude of the Fourier-transformed sampled time interval. Both methods demonstrated they can be used for real-time monitoring of ablation process.

This is clearly observed when proving that, in the case of the amplitude of the most significant acoustic oscillation, a greater amplitude of said oscillation was detected, a finding which we associate with the ablation of the paint finish material. This phenomenon occurred at the same time and with the same behavior as observed in LIBS, where a predominant presence of emission derived from the paint finish is detected during the first two pulses, but afterward diminishes and does not return to its previous intensity.

For the purpose of corroborating the behavior of the PILA monitoring using another criteria, the total sampled interval was calculated using Fourier transform, which showed that before the characteristic lines are inverted, a greater general magnitude of the frequency bands exists, which we associate with the paint finish ablation. The subsequent behavior is characterized by the decrease of the bands until they reach a relatively constant magnitude.

\section{Conclusions}

The aim of this work was to demonstrate the potential of PILA technique for monitoring the laser ablation of paint layers by using PILA technique.

In order to monitor the process by using the signal intensity, the most significant oscillation was detected in the acoustic signal, which diminished when ablating the substrate. In addition, the results suggest that the behavior of the FFT magnitude is similar to the one observed for the amplitude.

Using said analysis, a greater intensity can be observed in the frequency band associated with the paint, if compared to the intensity of the bands associated with the substrate.

In the LIBS analysis, the information about the presence of characteristic emission lines for each material, confirming that the PILA technique holds potential for qualitative monitoring of the ablation process of paint, was produced by using multi-pulse laser excitation. In resume, no differences in behavior of PILA results between single and multi-pulse regimes were observed despite the complexity of acoustic signal for the last regime.

\section{Acknowledgements}

The authors thank CONACYT for its financial support. This project was co-financed by the SIP-IPN 20150573 project.

\section{References}

[1] Asmus, J.E. (1986) More Light for Art Conservation. IEEE Circuits and Devices Magazine, 


\section{2, 6-15. http://dx.doi.org/10.1109/MCD.1986.6311800}

[2] Buccolieri, G., et al. (2013) Laser Cleaning of a Bronze Bell. Applied Surface Science, 272, 55-58. http://dx.doi.org/10.1016/j.apsusc.2012.03.132

[3] Gervais, A., et al. (2007) Cleaning Historical Metals: Performance of Laser Technology in Monument Preservation. In: Nimmrichter, J., Kautek, W. and Schreiner, M., Eds., Lasers in the Conservation of Artworks, Vol. 116, Springer, Berlin Heidelberg, 37-44.

[4] Koh, Y.S., et al. (2007) Laser Cleaning of Corroded Steel Surfaces: A Comparison with Mechanical Cleaning Methods. In: Nimmrichter, J., Kautek, W. and Schreiner, M., Eds., Lasers in the Conservation of Artworks, Vol. 116, Springer, Berlin Heidelberg, 13-20.

[5] Zapka, W., Ziemlich, W. and Tam, A.C. (1991) Efficient Pulsed Laser Removal of $0.2 \mu \mathrm{m}$ Sized Particles from a Solid Surface. Applied Physics Letters, 58, 2217-2219.

http://dx.doi.org/10.1063/1.104931

[6] Dyer, P.E., Farrar, S.R. and Key, P.H. (1992) Fast Time-Response Photoacoustic Studies and Modelling of KrF Laser Ablated YBa2Cu3O7. Applied Surface Science, 54, 255-263. http://dx.doi.org/10.1016/0169-4332(92)90053-Z

[7] Lu, Y.F., Lee, Y.P., Hong, M.H. and Low, T.S. (1997) Acoustic Wave Monitoring of Cleaning and Ablation during Excimer Laser Interaction with Copper Surfaces. Applied Surface Science, 119, 137-146. http://dx.doi.org/10.1016/S0169-4332(97)00188-8

[8] Reynaud, R., Ponce, L.V., Arronte, M.A., de Posada, E., Rodríguez, E. and Flores, T. (2009) Laser Induced Micro-Cracks Formation inside the Glass, LIBS, and PILA Measurements. Proceedings of SPIE 7499, Seventh Symposium Optics in Industry, Jalisco, 11 September 2009. http://dx.doi.org/10.1117/12.848981

[9] Navarrete, M., Villagrán-Muniz, M., Ponce, L. and Flores, T. (2003) Photoacoustic Detection of Microcracks Induced in BK7 Glass by Focused Laser Pulses. Optics and Lasers in Engineering, 40, 5-11. http://dx.doi.org/10.1016/S0143-8166(02)00066-0

[10] Fiedler, M. and Hess, P. (1990) Frequency Domain Analysis of Acoustic Resonances Excited with Single Laser Pulses. In: Murphy, J., Spicer, J.M., Aamodt, L. and Royce, B.H., Eds., Photoacoustic and Photothermal Phenomena II, Vol. 62, Springer, Berlin Heidelberg, 344-346.

[11] Flores, T., Ponce, L., Arronte, M. and de Posada, E. (2009) Free-Running and Q:Switched LIBS Measurements during the Laser Ablation of Prickle Pears Spines. Optics and Lasers in Engineering, 47, 578-583. http://dx.doi.org/10.1016/j.optlaseng.2008.10.006

[12] Arronte, M., Ortega, E., Ponce, L., de Posada, E., Rodriguez, E. and Flores, T. (2010) RealTime Monitoring of De-Thorning Process in Opunctia Nopalea by Using a PILA Technique. Electronic Journal Technical Acoustics, 1, 10.

[13] Moreira, L., et al. (2011) Sistema LIBS portable para la determinación de elementos químicos presentes en el deterioro de construcciones de valor patrimonial. Revista Cubana de Física, 28, 87-91.

[14] Kramida, A., Ralchenko, Y., Reader, J. and NIST ASD Team (2015) NIST Atomic Spectra Database (Ver. 5.3). National Institute of Standards and Technology, Gaithersburg. http://physics.nist.gov/asd

[15] Alvira, F.C., Orzi, D.J.O. and Bilmes, G.M. (2009) Surface Treatment Analyses of Car Bearings by Using Laser-Induced Breakdown Spectroscopy. Applied Spectroscopy, 63, 192-198. http://dx.doi.org/10.1366/000370209787392067 
Submit or recommend next manuscript to SCIRP and we will provide best service for you:

Accepting pre-submission inquiries through Email, Facebook, LinkedIn, Twitter, etc. A wide selection of journals (inclusive of 9 subjects, more than 200 journals)

Providing 24-hour high-quality service

User-friendly online submission system

Fair and swift peer-review system

Efficient typesetting and proofreading procedure

Display of the result of downloads and visits, as well as the number of cited articles

Maximum dissemination of your research work

Submit your manuscript at: http://papersubmission.scirp.org/

Or contact ojapps@scirp.org 